\title{
A Hydromechanical Perspective to Study the Effect of Body Acceleration through Stenosed Artery
}

\author{
Sapna Ratan Shah \\ Bio-Mathematical Lab 34, School of Computational and Integrative Sciences, \\ Jawaharlal Nehru University, New Delhi-110067, India. \\ Corresponding author: sapnarshah@mail.jnu.ac.in \\ Pushkar Kumar \\ Bio-Mathematical Lab 34, School of Computational and Integrative Sciences, \\ Jawaharlal Nehru University, New Delhi-110067, India. \\ E-mail: puskar95 sit@jnu.ac.in
}

(Received on November 21, 2020; Accepted on September 11, 2021)

\begin{abstract}
The spread of numerous deadly diseases such as Thrombosis, Diabetes, Atherosclerosis and other cardiac diseases, carry on to be major root of demise and growing public curiosity about the prevention and treatment of such fatal disorders. Body acceleration has very important role on the flow through stenosed artery. In this research work a problem for irregular development in the inner wall of the artery is known atherosclerosis that settled as a result of buildup due to cholesterol on the arterial wall has been discussed. In this work the effects of body acceleration, slip velocity in presence of catheter on the wall shear, velocity profile and flow rate reveal the graphical finding for pulsatile blood flow in narrow blood vessels. Here it is shown that flow rate, velocity and shear stress escalate as body acceleration increases.
\end{abstract}

Keywords- Pulsatile blood flow, Slip velocity, Wall shear stress, Constricted artery, Thrombosis.

\section{Introduction}

In the present time, the attention in hemodynamic studies has developed significantly because in realty, many cardiac disorders are directly associated to the flow of blood and its conditions in the artery. Apparently enforced body acceleration has a key character on flow of blood. A study for irregular growth in the inner layer of the blood vessel is named stenosis that settled in order to buildup blood glucose in the inner layer of artery (Akbar \& Butt, 2016). Some studies (Ellahi et al., 2014; Nadeem et al., 2011) have been done for the flow features of blood in a blood vessel with stenosis and without stenosis through presenting non-Newtonian fluid flows of various type to denote the blood flow characteristics. As blood is made of white cells, red cells, plasma and behaves like a fluid which has constant viscosity and at very less rate of shear in capillaries. Some researchers (Neofytou \& Drikakis, 2003; Rathod \& Ravi, 2014) have represented a widespread Newtonian model taken mostly for flow at great shear when blood performs as Newtonian fluid.

Several theoretical and experimental analyses (Nadeem et al., 2011; Rathod, \& Ravi, 2014; Varshney et al., 2010) were done to investigate the flow features in the occurrence of stenosed artery. Among several models proposed to blood, Casson fluid model (Ellahi et al., 2013) which explains the stress (yield) of blood has extensively advised for describing the movement characteristics of flow of blood in smaller diameter vessels. Returning of blood to the heart is responsible for the pulsatile nature in all arterial vessels. The heart refuses, further receives the blood in broken sequences known systole and diastole. And then heart relaxed while diastole and 
no blood are driven out whereas in the systole the heart pumped out the blood. In some papers (Biswas \& Chakraborty, 2010; Nadeem et al., 2011) the pulsatile nature of flow with nonNewtonian characteristics of blood flow along an artery with stenosis in order to present mathematical modelling of blood as a Casson fluid has been considered for study. Some of the studies (Rahbari et al., 2017; Varshney et al., 2010) have been done for pulsatile nature of flow through artery which is having stenosis.

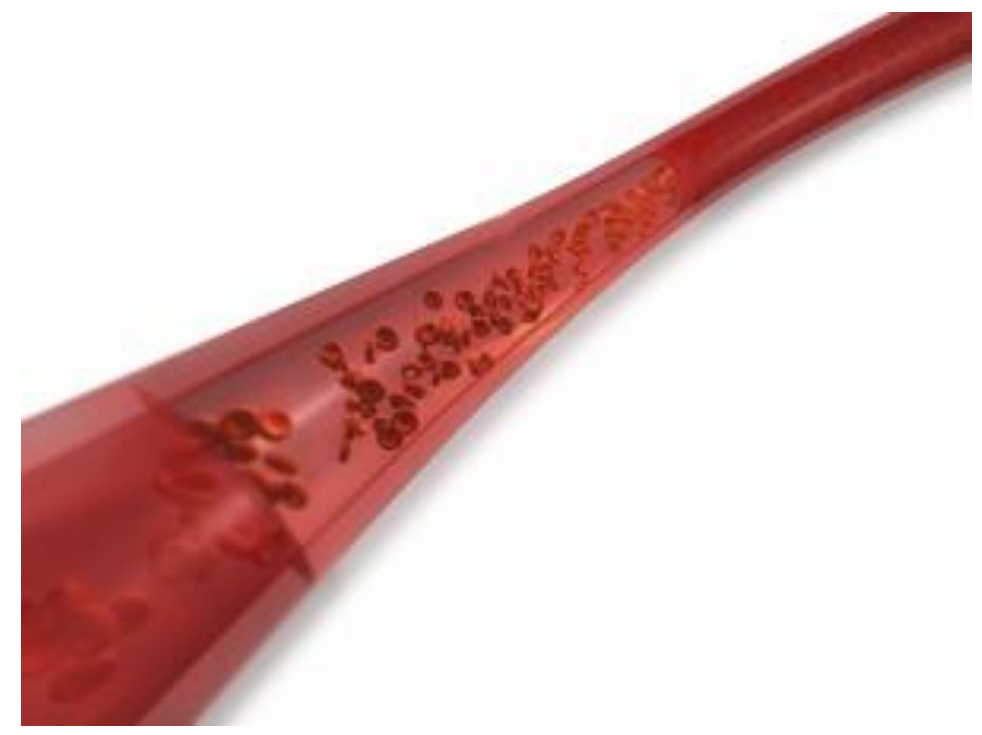

Figure 1. Blood flow in an artery.

In some more studies (Ellahi et al., 2014; Rahbari et al., 2017; Rathod \& Ravi, 2014) the pulsatile nature of blood with stenosed artery modeling under the condition of Herschel-Bulkley using a perturbation scheme has been done. In these studies, it has been observed that the pressure gradient increased with increasing values of yield stress. This has also been noticed that the flow is increased significantly with increase in stenotic height. Several theoretical and experimental studied have been done to get the results in the presence of slip at the tube wall (Ajdari et al., 2017; Neofytou \& Drikakis, 2003). On the interpretation of experimental and theoretical studies with condition of slip, this is inadequate to overlook the slip condition in flow through blood vessels. This is noticed in previous work, that the researchers are not able to find the exact expression to find the effects of slip velocity. Therefore, it was necessary to derive a expression to find slip velocity. In theoretical study of (Akbar et al., 2011; Ellahi et al., 2013) the effects of slip velocity parameter on flow of blood in artery with stenosis have been analyzed. In the study of (Nadeem et al., 2011; Nagarani \& Sarojamma, 2008) a mathematical model has been developed with slip condition at constricted wall for the impact of blood flow along stenosed arterial segments. Pulsatile nature of blood for a catheterized blood vessel with distinct shape of stenosis was shown (Varshney et al., 2010). So, the purpose of this analysis is to find the characteristic of flow of blood through an artery as a Newtonian model. The impact of slip velocity and body acceleration in existence of catheter have been obtained for pulsatile blood flow. 


\section{Mathematical Formulation}

Considering flow of blood is pulsatile nature of blood with external body acceleration is applied along the wall with stenosis due to slip velocity has been studied. The laminar, axially symmetric, fully developed and one dimensional, Newtonian fluid through a catheterized artery with mild stenosis have been taken. The catheter can be considered as rigid tube with the radius $R_{1}$ as in Figure 1. Wall of the tube has been taken rigid. The geometry of the stenosis is given in equation (1).

$$
\left.\overline{\mathrm{R}}(\overline{\mathrm{z}})=\begin{array}{ll}
\overline{\mathrm{R}_{0}}-\frac{\overline{\delta_{\mathrm{x}}}}{2}\left(1+\cos \left(\frac{\pi \overline{\mathrm{Z}}}{\mathrm{z}_{0}}\right)\right), & \text { for }|\overline{\mathrm{z}}| \leq \overline{\mathrm{z}_{0}} \\
\overline{\mathrm{R}_{0}}, & \text { for }|\overline{\mathrm{z}}|>\overline{\mathrm{z}_{0}},
\end{array}\right\}
$$

Where, $R_{0}$ is constant radius of the artery, $\bar{R}(\bar{z})$ is stenotic segment radius, $\overline{z_{0}}$ is half distance, $\overline{\delta_{s}}$ is maximum height.

The governing equations by $[5,8]$ :

$$
\begin{aligned}
& \bar{\rho}\left(\frac{\partial \overline{\mathrm{u}}}{\partial \overline{\mathrm{t}}}\right)=-\left(\frac{\partial \overline{\mathrm{p}}}{\partial \overline{\mathrm{z}}}\right)-\left(\frac{1}{\mathrm{r}}\right) \frac{\partial \overline{\tau \mathrm{r}}}{\partial \overline{\mathrm{r}}}+\overline{\mathrm{F}}(\overline{\mathrm{t}}) \\
& \frac{\partial \overline{\mathrm{p}}}{\partial \overline{\mathrm{r}}}=0 \\
& \frac{\partial \overline{\mathrm{p}}}{\partial \bar{\theta}}=0
\end{aligned}
$$

where, $\overline{\mathrm{p}}$ is pressure, $\overline{\mathrm{u}}$ is axial velocity, $\bar{\tau}$ is shear stress, $\bar{\rho}$ is density of the blood, $\overline{\mathrm{t}}$ is time.

Blood has treated as Newtonian fluid and can be written as below:

$\bar{\tau}=-\bar{\mu}\left(\frac{\partial \overline{\mathbf{u}}}{\partial \overline{\mathrm{r}}}\right)$

$\bar{\mu}=$ Shear viscosity.

$$
\begin{array}{lll}
\text { (i) } \overline{\mathrm{u}}=\overline{\mathrm{u}_{\mathrm{S}}} & \text { at } & \overline{\mathrm{r}}=\overline{\mathrm{R}}(\overline{\mathrm{z}}) \\
\text { (ii) } \overline{\mathrm{u}}=0 & \text { at } & \overline{\mathrm{r}}=\overline{\mathrm{R}_{1}}
\end{array}
$$

Here, $\overline{\mathrm{R}_{1}}$ is radius of the catheter, $\overline{\mathrm{u}_{\mathrm{S}}}$ is Slip velocity.

$$
\left(-\frac{\partial \overline{\mathrm{p}}}{\partial \overline{\mathrm{z}}}\right)(\overline{\mathrm{z}}, \overline{\mathrm{t}})=\mathrm{A}_{0}+\mathrm{A}_{1} \cos \left(\overline{\omega_{\mathrm{p}} \mathrm{t}}\right), \quad \mathrm{t} \geq 0
$$


Here, $A_{1}$ is amplitude, $A_{0}$ is Pressure gradient.

$\overline{\mathrm{F}}(\overline{\mathrm{t}})=\mathrm{a}_{0} \cos \left(\overline{\omega_{\mathrm{b}}} \overline{\mathrm{t}}+\varphi\right)$

$\mathrm{a}_{0}$ is amplitude.

Variables to make non-dimensional;

$$
\begin{aligned}
& \mathrm{u}=\overline{\mathrm{u}} /\left(\frac{\mathrm{A}_{0} \overline{\mathrm{R}}_{0}^{2}}{4 \bar{\mu}}\right), \mathrm{z}=\frac{\overline{\mathrm{z}}}{\mathrm{R}_{0}}, \mathrm{R}(\mathrm{z})=\frac{\overline{\mathrm{R}}(\overline{\mathrm{z}})}{\overline{\mathrm{R}_{0}}}, \mathrm{r}=\frac{\overline{\mathrm{r}}}{\mathrm{R}_{0}}, \mathrm{t}=\overline{\mathrm{t}} \overline{\mathrm{p}}, \omega=\frac{\overline{\omega_{\mathrm{b}}}}{\overline{\omega_{\mathrm{p}}}}, \delta_{\mathrm{s}}=\frac{\overline{\delta_{\mathrm{S}}}}{\overline{\overline{\mathrm{R}_{0}}}} \\
& \mathrm{u}=\overline{\mathrm{u}_{\mathrm{S}}} /\left(\frac{\mathrm{A}_{0} \overline{\mathrm{R}}_{0}^{2}}{4 \bar{\mu}}\right), \tau=\bar{\tau} /\left(\frac{\mathrm{A}_{0} \overline{\mathrm{R}}_{0}}{2}\right), \alpha^{2}=\frac{\overline{\mathrm{R}_{0}^{2}} \overline{\omega_{\mathrm{p}}} \rho}{\bar{\mu}}, \mathrm{e}=\frac{\mathrm{A}_{1}}{\mathrm{~A}_{0}}, \mathrm{~B}=\frac{\mathrm{a}_{0}}{\mathrm{~A}_{0}}, \mathrm{R}_{1}=\frac{\overline{\mathrm{R}_{1}}}{\overline{\mathrm{R}_{0}}}
\end{aligned}
$$

where, $\overline{R_{0}}$ is radius of the normal artery, $A_{0}$ is pressure gradient component, $\overline{\omega_{\mathrm{p}}}$ is frequency oscillation and $\left(\frac{\mathrm{A}_{0} \overline{\mathrm{R}}_{0}^{2}}{4 \bar{\mu}}\right)$, denotes the central line velocity.

$\alpha^{2}\left(\frac{\partial \mathrm{u}}{\partial \mathrm{t}}\right)=4(1+\mathrm{ecos} \mathrm{t})+4 \mathrm{~B} \cos (\omega \mathrm{B}+\varphi)-(2 / \mathrm{r})\left(\frac{\partial(\mathrm{r} \tau \mathrm{r}}{\partial \mathrm{r}}\right)$

Here, $\alpha^{2}=\left(\frac{\omega_{\mathrm{p}} \mathrm{R}_{0}^{2}}{\mu / \rho}\right)$ is called Womersley frequency parameter.

$$
\tau=-\frac{1}{2}\left(\frac{\partial \mathrm{u}}{\partial \mathrm{r}}\right)
$$

By putting the value of $\tau$ in Eqn. (11) we have;

$\alpha^{2}\left(\frac{\partial \mathrm{u}}{\partial \mathrm{t}}\right)=4(1+\mathrm{ecost})+4 \mathrm{~B} \cos (\omega \mathrm{B}+\varphi)-(1 / \mathrm{r})\left(\frac{\partial}{\partial \mathrm{r}}\left(\mathrm{r} \frac{\partial \mathrm{u}}{\partial \mathrm{r}}\right)\right)$

The equation no. (6) and (7) are as;

(i) $\mathrm{u}=\mathrm{u}_{\mathrm{S}} \quad$ at $\mathrm{r}=\mathrm{R}(\mathrm{z})$

(i) $\mathrm{u}=0$ at $\mathrm{r}=\mathrm{R}_{1}(\mathrm{z})$

The dimensionless form of equation (1) is as;

$$
\left.R(z)=\begin{array}{ll}
1-\frac{\delta_{S}}{2}\left(1+\cos \left(\frac{\pi \mathrm{Z}}{\mathrm{z}_{0}}\right)\right), & \text { for }|z| \leq z_{0} \\
1, & \text { for }|z|>z_{0},
\end{array}\right\}
$$


$\mu_{\mathrm{e}}=\pi\left(\frac{\mathrm{dp}}{\mathrm{dz}}\right) \mathrm{R}^{4} / \mathrm{Q}(\mathrm{z}, \mathrm{t})$

$\mu_{\mathrm{e}}=\mathrm{R}^{4}(1+$ ecost $) / \mathrm{Q}(\mathrm{z}, \mathrm{t})$

\section{Solution of the Problem}

The velocity of blood may be stated as below;

$\mathrm{u}(\mathrm{z}, \mathrm{r}, \mathrm{t})=\mathrm{u}_{0}(\mathrm{z}, \mathrm{r}, \mathrm{t})+\alpha^{2} \mathrm{u}_{1}(\mathrm{z}, \mathrm{r}, \mathrm{t})+\ldots$.

Substituting Eqn. (19) in Eqn. (13) and in eqn. (14) respectively;

$\frac{\partial}{\partial \mathrm{r}}\left(\mathrm{r} \frac{\partial \mathrm{u}_{0}}{\partial \mathrm{r}}\right)=4 \mathrm{r}[(1+\mathrm{ecost})+4 \mathrm{~B} \cos (\omega \mathrm{B}+\varphi)]$

$\frac{\partial \mathrm{u}_{0}}{\partial \mathrm{r}}=\frac{1}{\mathrm{r}} \frac{\partial}{\partial \mathrm{r}}\left(\mathrm{r} \frac{\partial \mathrm{u}_{1}}{\partial \mathrm{r}}\right)$

$\mathrm{u}_{0}=\mathrm{u}_{\mathrm{S}}$ and $\mathrm{u}_{1}=0$ at $\mathrm{r}=\mathrm{R}(\mathrm{z})$

$\mathrm{u}_{0}=0 \quad$ and $\quad \mathrm{u}_{1}=0$ at $\quad \mathrm{r}=\mathrm{R}_{1}(\mathrm{z})$

To determine $u_{0}$ and $u_{1}$ Integrating equation (20) and (21) using boundary conditions (22), (23);

$\mathrm{u}_{0}=\mathrm{f}(\mathrm{t})\left(\mathrm{R}_{0}^{2}-\mathrm{r}^{2}\right)+\frac{\ln \left(\mathrm{r} / \mathrm{R}_{1}\right)}{\ln \left(\mathrm{R} / \mathrm{R}_{1}\right)}\left(\mathrm{u}_{\mathrm{s}}+\mathrm{f}(\mathrm{t})\left(\mathrm{R}^{2}-\mathrm{R}_{1}^{2}\right)\right)$

where $f(t)=[(1+$ ecost $)+B \cos (\omega \mathrm{c}+\varphi)]$

$\mathrm{u}_{1}=\mathrm{D}\left[\left(\left(\mathrm{R}_{1}^{2} \mathrm{r}^{2} / 4-\mathrm{r}^{4} / 16\right)-3\left(\mathrm{R}_{1}^{4} / 16\right)+\frac{\left(\mathrm{R}^{2}-\mathrm{R}_{1}^{2}\right)}{4 \ln \left(\mathrm{R} / \mathrm{R}_{1}\right)}\left(\mathrm{r}^{2} \ln \left(\mathrm{r} / \mathrm{R}_{1}\right)-\mathrm{r}^{2}+\mathrm{R}_{1}^{2}\right)\right.\right.$

$+\frac{\ln \left(\mathrm{R}_{1} / \mathrm{r}\right)}{\ln \left(\mathrm{R} / \mathrm{R}_{1}\right)}\left[\left(\mathrm{R}_{1}^{2} \mathrm{R}^{2} / 4\right)-\left(\mathrm{R}^{4} / 16\right)\right)-3\left(\mathrm{R}_{1}^{4} / 16\right)+\frac{\left(\mathrm{R}^{2}-\mathrm{R}_{1}^{2}\right)}{4 \ln \left(\mathrm{R} / \mathrm{R}_{1}\right)}\left(\ln \left(\mathrm{R} / \mathrm{R}_{1}\right) \mathrm{R}^{2}-\mathrm{R}^{2}+\mathrm{R}_{1}^{2}\right)$

$\mathrm{u}(\mathrm{z}, \mathrm{r}, \mathrm{t})=\mathrm{f}(\mathrm{t})\left[\left(\mathrm{R}_{1}^{2}-\mathrm{r}^{2}\right)+\frac{\ln \left(\mathrm{r} / \mathrm{R}_{1}\right)}{4 \ln \left(\mathrm{R} / \mathrm{R}_{1}\right)}\left(\mathrm{u}_{\mathrm{s}}+\mathrm{f}(\mathrm{t})\left(\mathrm{R}^{2}-\mathrm{R}_{1}^{2}\right)\right]+\alpha^{2} \mathrm{D}\left(\mathrm{C}_{1}+\mathrm{C}_{2}+\mathrm{C}_{3}+\mathrm{C}_{4}\right)\right.$

where;

$\mathrm{C}_{1}=\left[\left(\mathrm{R}_{1}^{2} \mathrm{r}^{2} / 4\right)-\left(\mathrm{r}^{4} / 16\right)-3\left(\mathrm{R}_{1}^{4} / 16\right)\right], \mathrm{C}_{2}=\frac{\left(\mathrm{R}^{2}-\mathrm{R}_{1}^{2}\right)}{4 \ln \left(\mathrm{R} / \mathrm{R}_{1}\right)}\left(\mathrm{r}^{2} \ln \left(\mathrm{r} / \mathrm{R}_{1}\right)-\mathrm{r}^{2}+\mathrm{R}_{1}^{2}\right)$,
$\mathrm{C}_{3}=\frac{\ln \left(\mathrm{R}_{1} / \mathrm{r}\right)}{\ln \left(\mathrm{R} / \mathrm{R}_{1}\right)}\left[\left(\mathrm{R}_{1}^{2} \mathrm{R}^{2} / 4\right)-\left(\mathrm{R}^{4} / 16\right)\right)-3\left(\mathrm{R}_{1}^{4} / 16\right), \mathrm{C}_{4}=\frac{\left(\mathrm{R}^{2}-\mathrm{R}_{1}^{2}\right)}{4 \ln \left(\mathrm{R} / \mathrm{R}_{1}\right)}\left(\ln \left(\mathrm{R} / \mathrm{R}_{1}\right) \mathrm{R}^{2}-\mathrm{R}^{2}+\mathrm{R}_{1}^{2}\right)$.

The wall shear stress has been found by putting velocity from equation (24) and (25). 
$\tau_{\omega}=\left[-\frac{1}{2}\left(\frac{\partial \mathrm{u}_{0}}{\partial \mathrm{r}}\right)+\alpha^{2}\left(\frac{\partial \mathrm{u}_{1}}{\partial \mathrm{r}}\right)\right]_{\mathrm{r}=\mathrm{R}(\mathrm{z})}$

$\tau_{\omega}=\left[\mathrm{Rf}(\mathrm{t})-\frac{1}{2 \ln \left(\mathrm{R} / \mathrm{R}_{1}\right)}\left(\mathrm{u}_{\mathrm{s}}+\mathrm{f}(\mathrm{t})\left(\mathrm{R}^{2}-\mathrm{R}_{1}^{2}\right)\right)-\frac{\alpha^{2} \mathrm{D}}{2}\left(\mathrm{R}_{1}^{2} \mathrm{R} / 2\right)-\left(\mathrm{R}^{3} / 4\right)\right)$

$+\frac{\left(\mathrm{R}^{2}-\mathrm{R}_{1}^{2}\right)}{4 \ln \left(\mathrm{R} / \mathrm{R}_{1}\right)}\left(2 \mathrm{R} \ln \left(\mathrm{R} / \mathrm{R}_{1}-\mathrm{R}\right)-\left(\frac{1}{\mathrm{R} \ln \left(\mathrm{R} / \mathrm{R}_{1}\right)}\left[\left(\mathrm{R}_{1}^{2} \mathrm{R}^{2} / 4\right)-\left(\mathrm{R}^{4} / 16\right)\right)-3\left(\mathrm{R}_{1}^{4} / 16\right)\right]+\right.$

$\left.\frac{\left(\mathrm{R}^{2}-\mathrm{R}_{1}^{2}\right)}{4 \ln \left(\mathrm{R} / \mathrm{R}_{1}\right)}\left(\ln \left(\mathrm{R} / \mathrm{R}_{1}\right) \mathrm{R}^{2}-\mathrm{R}^{2}+\mathrm{R}_{1}^{2}\right)\right)$

The flow rate is as below;

$$
\begin{aligned}
& \left.\mathrm{Q}(\mathrm{z}, \mathrm{t})=\mathrm{f}(\mathrm{t})\left(2 \mathrm{R}_{1}^{2} \mathrm{R}^{2}-\mathrm{R}^{4}-\mathrm{R}_{1}^{2}\right)\right)+\frac{1}{\ln \left(\mathrm{R} / \mathrm{R}_{1}\right)}\left[\left(\mathrm{u}_{\mathrm{s}}+\mathrm{f}(\mathrm{t})\left(\mathrm{R}^{2}-\mathrm{R}_{1}^{2}\right)\right)\right. \\
& \mathrm{x}\left(2 \ln \left(\mathrm{R} / \mathrm{R}_{1}\right) \mathrm{R}^{2}-\mathrm{R}^{2}+\mathrm{R}_{1}^{2}\right)+\alpha^{2} \mathrm{D}\left(\mathrm{B}_{1}+\frac{\left(\mathrm{R}^{2}-\mathrm{R}_{1}^{2}\right)}{\ln \left(\mathrm{R} / \mathrm{R}_{1}\right)} \mathrm{B}_{2} \mathrm{~B}_{3} \mathrm{~B}_{4}\right)
\end{aligned}
$$

where;

$$
\begin{aligned}
& \left.\mathrm{B}_{1}=\left(\mathrm{R}_{1}^{2} \mathrm{R}^{4} / 4\right)-\left(\mathrm{R}^{6} / 24\right)-\left(3 \mathrm{R}_{1}^{4} \mathrm{R}^{2} / 8\right)-\left(5 \mathrm{R}_{1}^{6} / 24\right)+\left(3 \mathrm{R}_{1}^{6} / 8\right)\right), \\
& \left.\mathrm{B}_{2}=\left(\ln \left(\mathrm{R} / \mathrm{R}_{1}\right)\left(\mathrm{R}^{4} / 4\right)-\left(5 \mathrm{R}^{4} / 16\right)+\mathrm{R}_{1}^{2} \mathrm{R}^{2} / 2\right)+\left(3 \mathrm{R}_{1}^{4} / 16\right)\right), \\
& \left.\mathrm{B}_{3}=\frac{1}{\ln \left(\mathrm{R} / \mathrm{R}_{1}\right)}\left(\mathrm{R}_{1}^{2} \mathrm{R}^{2}-\left(\mathrm{R}^{4} / 4\right)-\left(3 \mathrm{R}_{1}^{4} / 4\right)\right)+\frac{\left(\mathrm{R}^{2}-\mathrm{R}_{1}^{2}\right)}{\ln \left(\mathrm{R} / \mathrm{R}_{1}\right)} \ln \left(\mathrm{R} / \mathrm{R}_{1}\right)\left(\mathrm{R}^{2}-\mathrm{R}^{2}+\mathrm{R}_{1}^{2}\right)\right), \\
& \mathrm{B}_{4}=\left(\ln \left(\mathrm{R} / \mathrm{R}_{1}\right)\left(\mathrm{R}^{2} / 2\right)+\left(\mathrm{R}^{2} / 4\right)+\left(\mathrm{R}_{1}^{2} / 4\right) .\right.
\end{aligned}
$$

Effective viscosity is represented from equation (18) and (29).

$$
\begin{aligned}
& \mu_{\mathrm{e}}=\mathrm{R}^{4}(1+e \cos t)\left[f ( t ) \left(\left(2 \mathrm{R}_{1}^{2} \mathrm{R}^{2}-\mathrm{R}^{4}+\mathrm{R}_{1}^{4}\right)+\frac{1}{\ln \left(\mathrm{R} / \mathrm{R}_{1}\right)}\left(\mathrm{u}_{\mathrm{s}}+\mathrm{f}(\mathrm{t})\left(\mathrm{R}^{2}-\mathrm{R}_{1}^{2}\right)\right)\right.\right. \\
& \left.\left.\mathrm{x} 2 \ln \left(\mathrm{R} / \mathrm{R}_{1}\right)\left(\mathrm{R}^{2}-\mathrm{R}^{2}+\mathrm{R}_{1}^{2}\right)\right)+\alpha^{2} \mathrm{D}\left(\mathrm{B}_{1}+\frac{\left(\mathrm{R}^{2}-\mathrm{R}_{1}^{2}\right)}{\ln \left(\mathrm{R} / \mathrm{R}_{1}\right)} \mathrm{B}_{2} \mathrm{~B}_{3} \mathrm{~B}_{4}\right)\right]^{-1}
\end{aligned}
$$

\section{Results and Discussion}

The main objective of research work is to examine the impact of acceleration in presence of catheterized stenosed artery. Effect of slip velocity has also been examined in the presence of catheterized stenosed artery. Blood flow has assumed as Newtonian flow. The governing equation has been solved by perturbation technique. The influence of Womersley frequency parameter has been seen which is very small. With the help of MATLAB computer codes have developed for numerical results for viscosity, flow rate, wall shear stress and velocity. All parameter values have been taken from the literature of the research area (Varshney et al., 2010) to obtain the 
different profiles of blood flow. It is significant to obtain the configuration of profile of velocity as the exhaustive explanation of flow field has been given by profile of velocity.

And changes in velocity in axial direction with the distance in radial direction for the following parameters $\omega=1, e=1, z=0, \phi=0.2, u_{s}=0.05, \alpha=0.5$ growth of cholesterol or stenosis has been shown in Figure 2 . The body acceleration has been represented by a parameter and it is assumed between 0 to 2 . The range of pressure gradient parameter is considered between 0 to 0.5 . And the magnitude of lead angle is considered as 0.2. So, from the figure it is anticipated that due to body acceleration the velocity is more and increases speedily as the body acceleration rises. This is also observed that velocity increased as there is an increase in body acceleration and body acceleration increases hence the plug flow region contract and due to that change, there will be more blood flow which takes place in the artery.

The changes in flow rate in presence of pressure gradient for distinct values of body acceleration along with the values $R_{1}=0.2, \alpha=0.1, t=1, u_{s}=0.1$ have been shown in Figure 3. It has shown in this figure that the flow drops as height of stenosis increases (Rathod \& Ravi, 2014). The flow rate is examined minimum at $e=0$. The maximum and minimum results in the rate of flow is found with $B=0.1, u_{s}=.1, \delta_{s}=0$ and $B=0.0, u_{s}=0.1, \delta_{s}=0.1$, this can be seen from the graph as well. It is also depicted from the graph that the slip velocity and body acceleration boost the flow rate (Nadeem et al., 2011). Body acceleration along with slip velocity increases the rate of flow, this is because of increasement of width region of plug flow.

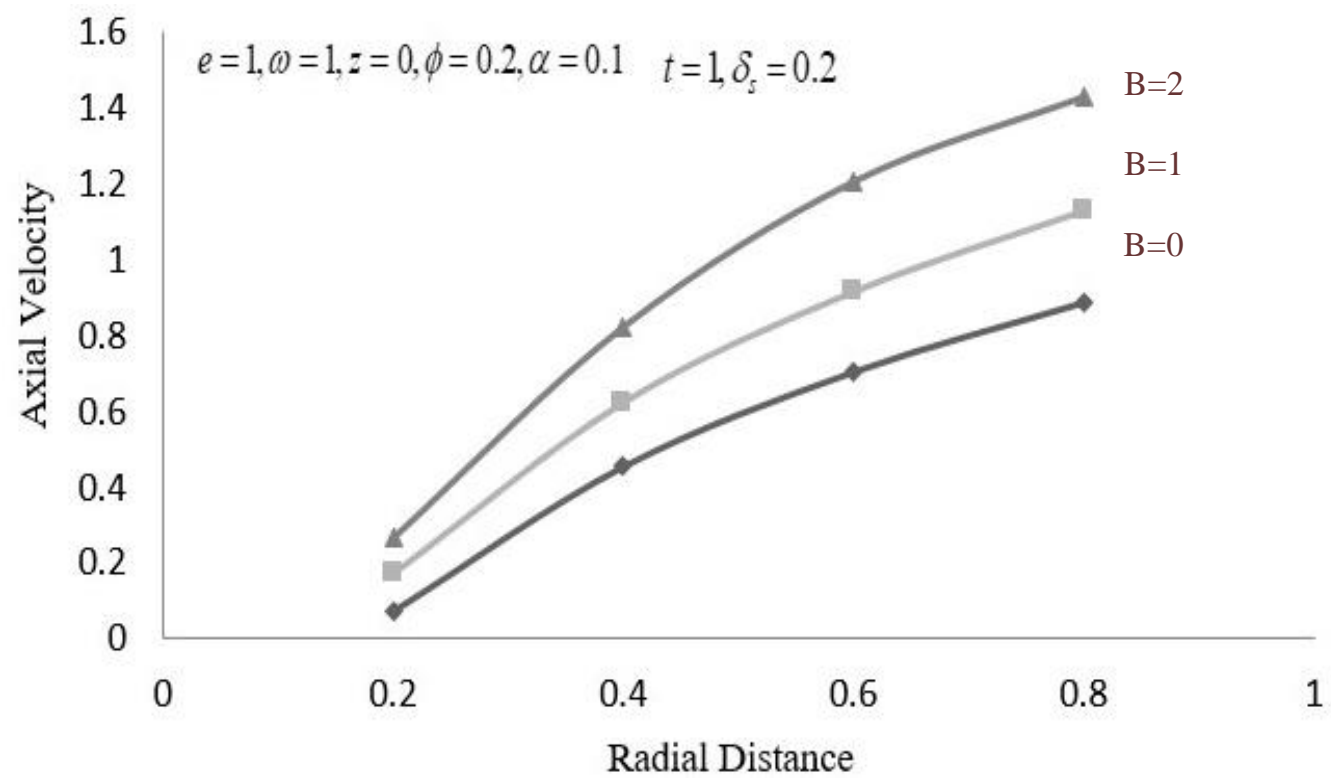

Figure 2. Axial velocity with radial distance for different value of body acceleration. 


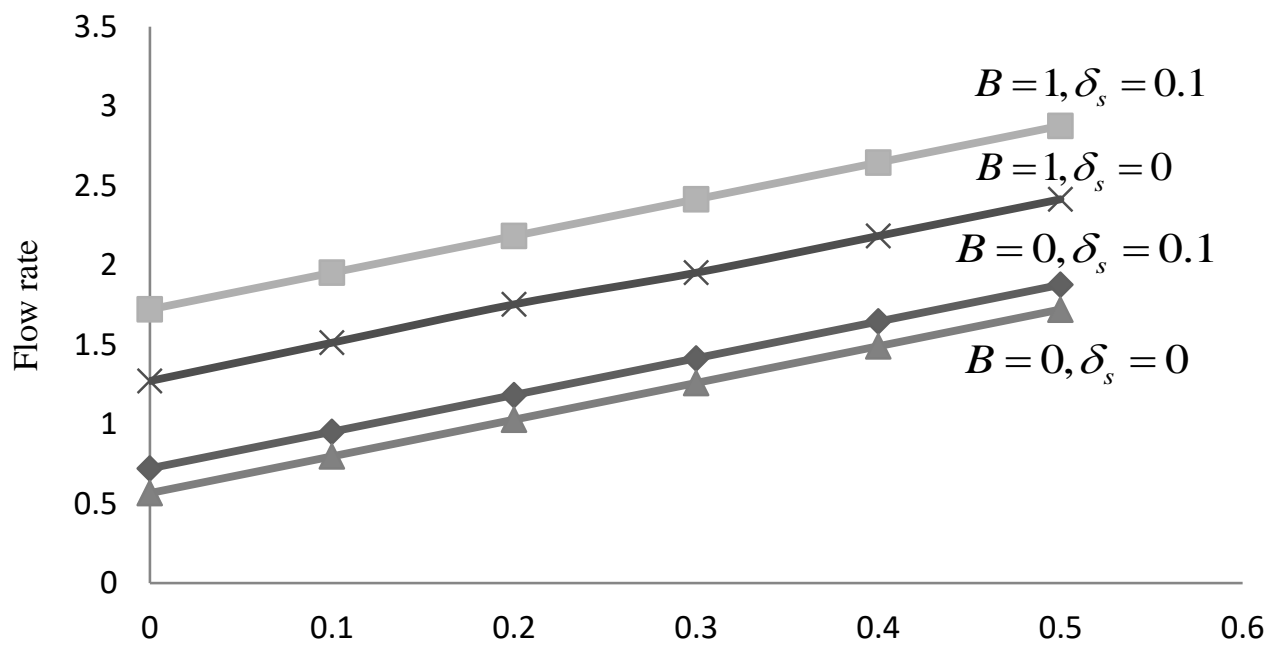

Pressure gradient

Figure 3. Rate of flow $\mathrm{Q}$ with pressure gradiente for $\mathrm{B}$ and $\delta_{\mathrm{s}}$

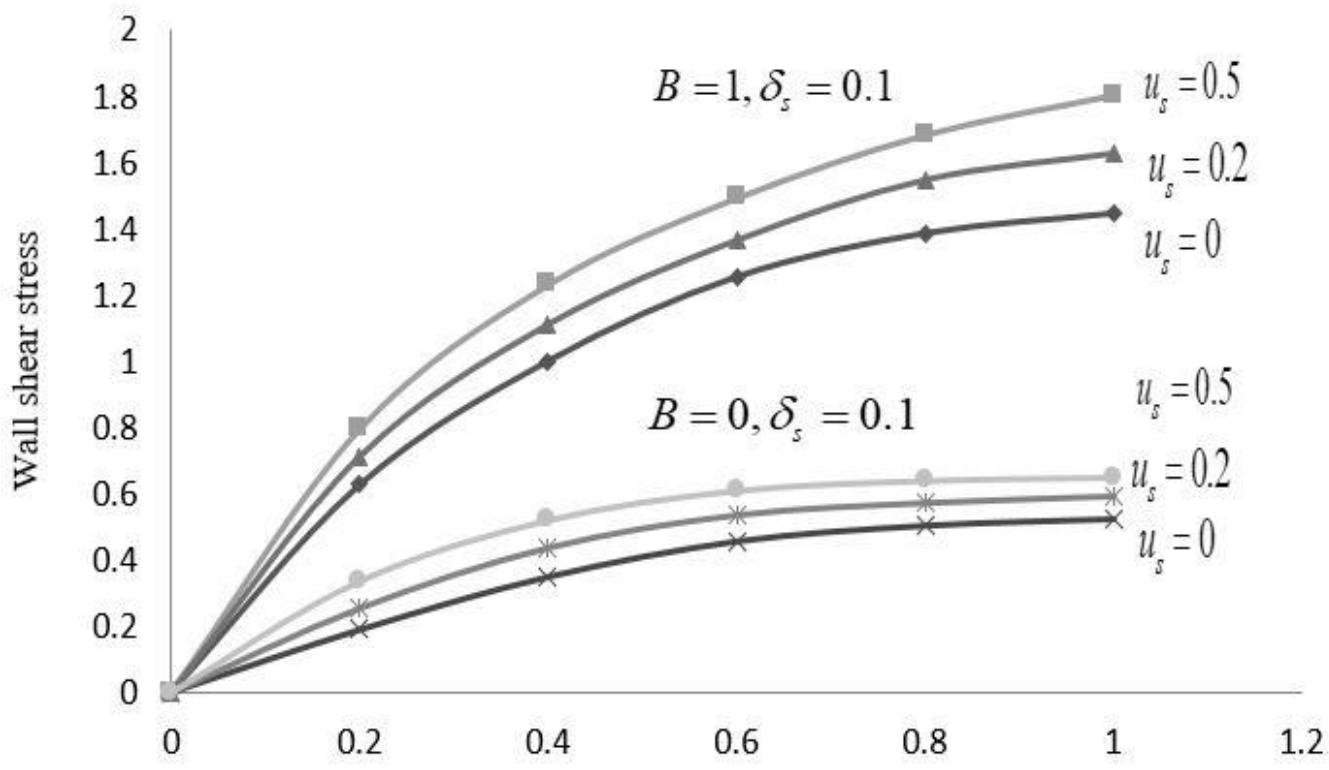

Catheter radius

Figure 4. Shear stress with catheter radius for slip velocity.

Figure 4 denotes the changes in flow characteristic because of catheter for distinct values of slip velocity in artery under stenotic condition while keeping all others parameters constant taken as ( $\left.B=1, \delta_{s}=0.2, \alpha=0.1, \phi=0.2, e=1, t=1, \omega=1, z=0, z_{0}=0\right)$. It may also effortlessly notice 
that as the radius of catheter rises, the stress escalates. Whereas, it has also seen that the velocity profile raises wall shear stress reduced in an artery (Nagarani \& Sarojamma, 2008).

\section{Conclusions}

It is revealed in this work that due to the presence of catheter, wall shear increases, which will also depend on the catheter's size. Body acceleration raises the velocity and flow escalates. Whereas it has obtained that wall shear is significantly a decrease as slip velocity increases. It has also revealed that the axial velocity escalates as wall slip grows. And flow also rises with the increasing values of slip parameter. It has revealed from the work that there is a significant influence of slip velocity and body acceleration on the profile of flow. In this research work a parameter which plays a very important role is body acceleration parameter this parameter shows quantitative changes as well as qualitative changes in velocity profiles. As a consequence of analysis, the wall slip in artery under stenotic condition, may play a vital role in flow problems. Due to fall in the wall slip the wall shear stress increases. This model is very useful for bioengineering and bio-mathematical fields to examine the effects of the various parameters and to explore the experimental results for many biological equipment and future research.

\section{Conflict of Interest}

The corresponding author on behalf of all authors, states that there is no conflict of interest.

\section{Acknowledgments}

We would like to express our thanks to the SCIS, JNU, New Delhi, for giving the facility of MATLAB.

\section{References}

Ajdari, N., Vyas, C., Bogan, S.L., Lwaleed, B.A., \& Cousins, B.G. (2017). Gold nanoparticle interactions in human blood: a model evaluation. Nanomedicine: Nanotechnology Biology and Medicine, 13(4), 1531-1542.

Akbar, N.S., \& Butt, A.W. (2016). Bio mathematical venture for the metallic nanoparticles due to ciliary motion. Computer Methods and Programs in Biomedicine, 134, 43-51.

Biswas, D., \& Chakraborty, U.S. (2010). Two-layered pulsatile blood flow in a stenosed artery with body acceleration and slip at wall. Applications and Applied Mathematics: An International Journal, 5(2), $303-320$

Ellahi, R., Rahman, S.U., \& Nadeem, S. (2013). Analytical solutions of unsteady blood flow of jeffery fluid through stenosed arteries with permeable walls. Zeitschrift für Naturforschung, A68(8-9).

Ellahi, R., Rahman, S.U., Gulzar, M.M., Nadeem, S., \& Vafai, K. (2014). A mathematical study of nonNewtonian micropolar fluid in arterial blood flow through composite stenosis. Applied Mathematics and Information Sciences, 8(4), 1567-1573.

Akbar, N.S., Nadeem, S., \& Ali, M. (2011). Jeffrey fluid model for blood flow through a tapered artery with a stenosis. Journal of Mechanics in Medicine and Biology, 11(3), 529-545.

Nadeem, S., Akber, N.S., Hendi Awatif, A., \& Hayat, T. (2011). Power law fluid model for blood flow through a tapered artery with a stenosis. Applied Mathematics and Computation, 217(17), 7108-7116.

Nagarani, P., \& Sarojamma, G. (2008). Effect of body acceleration on pulsatile flow of casson fluid through a mild stenosed artery. Journal of Korea-Australia Rheology, 20(4), 189-196. 
Neofytou, P., \& Drikakis, D. (2003). Non-Newtonian flow instability in a channel with a sudden expansion. Journal of Non-Newtonian Fluid Mechanics, 111 (2-3), 127-150.

Rahbari, A., Fakour, M., Hamzehnezhad, A., Vakilabadi, M.A., \& Ganji, D.D. (2017). Heat transfer and fluid flow of blood with nanoparticles through porous vessels in a magnetic field: a quasi-one dimensional analytical approach. Mathematical Biosciences, 283, 38-47.

Rathod, V.P., \& Ravi, M. (2014). Blood flow through stenosed inclined tubes with periodic body acceleration in the presence of magnetic field and its applications to cardiovascular diseases. International Journal of Research in Engineering and Technology, 3(15), 96-101.

Varshney, G., Katiyar, V.K., \& Kumar, S. (2010). Effect of magnetic field on the blood flow in artery having multiple stenosis: a numerical study. International Journal of Engineering Science and Technology, 2(2), 67-82. 